\title{
Viridiana: pervivencia del surrealismo subversivo en la narrativa buñuelesca
}

\section{Viridiana: survival of the subversive surrealism in the buñuelesca narrative}

Ramón Navarrete-Galiano. Universidad de Sevilla

\section{Resumen:}

Viridiana (1961) fue una de las realizaciones más polémicas de Luis Buñuel. El filme generó un escándalo al ser tachada de blasfema por el Vaticano, lo que provocó su prohibición en España. Todavía, medio siglo después de su estreno, es una obra transgresora y reivindicativa, que muestra planteamientos y elementos surrealistas, en un discurso que se ajusta a los cánones de la más tradicional narrativa fílmica. Buñuel no abandonó su ideario surrealista ni en filmes como este, lo que convirtió su película en un elemento subversivo. Analizando las influencias, muchas galdosianas, y estructura de la película comprobamos la pervivencia surrealista y la intencionalidad de su autor.

Palabras clave:

Transgresión, censura, subversión, surrealismo.

Abstract:

Viridiana (1961) was one of the most controversial achievements of Luis Buñuel. The film spawned a scandal to be barred from blasphemous by the Vatican, which resulted in his ban in Spain. Yet, half a century after its premiere is a transgressor and demanding, showing approaches and surreal, items in a speech that conforms to the canons of the more traditional narrative film. Buñuel did not abandon his surrealist ideology or in films such as this, his film what became a subversive element. Analyzing influences, many galdosianas, and structure of the film we see surrealist persistence and the intent of the author.

Key Words:

Transgression, censorship, subversion, surrealism. 


\section{Introducción}

Se cumplen ${ }^{1}$ cincuenta años de la redacción por parte de Luis Buñuel y Julio Alejandro del guión de la película Viridiana (1961). El aragonés llevaba a cabo una idea planificada años atrás pero que finalmente pudo realizar a principios de la década de los sesenta, con el apoyo de la productora española Uninci. Una realización que supuso el regreso de Buñuel a España, tras 25 años de exilio voluntario. Sin embargo, esa vuelta estuvo repleta de bastantes avatares, ya que obtener los permisos de rodaje y que el guión obtuviera el placet de la Junta Superior de Censura fue un proceso largo, que tras superarlo derivó en un escándalo mundial, al estrenarse el filme.

Viridiana ha sido la película de Buñuel que más vicisitudes ha sufrido, así como la que ha levantado mayor polémica, ya que tras ganar la Palma de Oro en el Festival de Cannes de 1961 como película de nacionalidad española, fue prohibida por el Vaticano al calificarla de blasfema y sacrílega, lo que provocó el cese del entonces director general de cinematografía, José Muñoz Fontán, además de retirársele la titularidad hispana al filme. Esto último supuso para el Gobierno Español cierto descrédito internacional cuando la obra de Buñuel se empezó a estrenar en los cines de todo el mundo. Junto a ello, la productora española Uninci, que participó en este proyecto, perdió los derechos para su gestión, lo que llevó a un importante contencioso durante varios años (Salvador, 2006). La sola mención del proceso de gestación de la producción, así como su posterior estreno, todavía genera polémica y enfrentamientos (Boletín de la Academia, no 74: 13).

Viridiana era una película muy lejana en el tiempo de Un chien andalou (Un perro andaluz, 1928), que supuso el inicio del surrealismo cinematográfico, pero sin embargo todavía recogía elementos y características propias de esa corriente, que la convertían en un elemento subversivo, como muchas de las producciones surrealistas. Buñuel fue el único autor vanguardista que mantuvo muchos de sus conceptos e idearios originales a lo largo de toda su filmografía (Muñoz Molina, 2008: 5)². La idea original de esta película, según declaraciones de Buñuel, era una fantasía erótica que él tenía en la que suministraba un narcótico a la Reina Victoria Eugenia para abusar de ella, a la que unía la historia de una santa llamada Viridiana. A partir de esto, desarrolló toda una trama, pero sin un guión cerrado del todo, por lo que es lógico que se colaran sus fantasmas particulares. Analizar esta creación fílmica, adecuada por completo al Modo de Representación Institucional, permite comprender las pautas desarrolladas por Buñuel para incorporar los elementos su-

El texto empezó a redactarse en 1959, dado que según consta en la documentación oficial (Expediente 53.167. Caja 71.847. Archivos del Ministerio de Cultura) será en 1960 cuando se negocie por parte de Buñuel y Alejandro la venta del guión.

2 "Quizás el surrealismo, tan marcado por la palabrería de André Bretón y la autoindulgencia de sus seguidores, era un brebaje estimulante pero demasiado cabezón del que solo podían sacar provecho de verdad las mentes muy sólidas: Buñuel sobre todo con su cabeza de pedernal aragonés". 
rrealistas, amén de las influencias, que el realizador incorpora. Muchas de estas parten del mundo de Benito Pérez Galdós, que tanto atrajo al realizador aragonés, y de quien adaptó dos novelas, Tristana y Nazarín, con títulos homónimos en la producción cinematográfica.

Conocer el proceso que llevó a esta película a convertirse en un elemento crítico con el sistema y censurado por el régimen franquista, permite comprender las pautas surrealistas que Buñuel desarrolló a lo largo de su trayectoria y que pervivieron hasta el final de su trayectoria.

Por ello desbrozaremos el proceso de producción de la película, desde sus inicios, el borrador del primer guión, así como las pautas que marcó la censura, para llegar al momento final de su estreno en Cannes. Así comprenderemos el proceso de Buñuel para introducir piezas surrealistas con la intencionalidad subversiva que ese movimiento tuvo en sus orígenes.

\section{Una producción española censurada}

Buñuel decidió rodar Viridiana en España, a instancias de Uninci, y desde el Gobierno Español se facilitaron bastante los trámites para que el realizador aragonés efectuara aquí su trabajo. Por un lado, la distinción que Nazarín (1958) había obtenido desde el Vaticano hacía tener menos cautela con el realizador; por otra, las autoridades españolas tenían interés en que Buñuel rodase en España para mejorar su imagen política. Si el aragonés filmaba en nuestro país, eso podría suponer, de cara a la opinión internacional, que en España habían cambiado las cosas, que había libertad para que un hombre tan peculiar como Luis Buñuel, pudiese trabajar en su país sin trabas de ningún tipo.

El director estaba contratado por Gustavo Alatriste para rodar Viridiana, ya fuera en España o Méjico. De hecho, Buñuel firmó un acuerdo privado el 10 de agosto de 1960 con Alatriste en el que se comprometía a escribir un guión cinematográfico cuyo título provisional fue Viridiana. Asimismo se comprometía a dirigirla, por cuya labor recibiría 150.000 pesos si la rodaba en Méjico o 250.000 si era en España. Guión cuyos derechos Buñuel cede a Uninci posteriormente ${ }^{3}$. La trama argumental del filme era la siguiente:

La novicia Viridiana - a punto de tomar los hábitos- debe abandonar el convento para visitar a su tío don Jaime, quien le ha pagado los estudios. Durante su visita, don Jaime-impresionado por el parecido entre Viridiana y su

3 LUIS BUÑUEL PORTOLES y JULIO ALEJANDRO DE CASTRO autores del argumento y diálogos de “VIRIDIANA”, DECLARAN: Que con fecha veinticinco de noviembre de mil novecientos sesenta, han cedido todos los derechos sobre el mencionado argumento y diálogos a la Productora UNION INDUSTRIAL CINEMATOGRAFICA S. A. (UNINCI. S.A.), para la realización de una película del mismo título. Madrid, 25 de noviembre de 1960. Fdo.: Luis Buñuel. Fdo.: Julio Alejandro. 
difunta esposa- la adormece, vestida con el traje de novia de la muerta, e intenta poseerla pero finalmente no se atreve. Posteriormente intenta retenerla cuando ella quiere volver al convento; le miente diciéndole que ya no podrá ordenarse monja, porque la ha hecho suya mientras dormía. Esto aleja aún más a Viridiana de su tío, que -tras la marcha de ésta-se suicida. Viridiana, que se siente culpable del suicidio, renuncia a ser monja y se queda en la mansión a practicar la caridad cristiana, acogiendo a un grupo de vagabundos, a quienes brinda refugio y alimento. A la casa llega el hijo natural de su tío, Jorge, quien llevará adelante la casa y la finca de la misma. Los pobres acogidos por Viridiana saquearán la casa cuando están fuera los dueños. Al regresar intentan violar a Viridiana, mientras maniatan a Jorge, quien soborna a un mendigo para que asesine al que agreda a la joven.

Finalmente, Viridiana, tras la marcha de los pobres, abandonará su vida ascética y decidirá iniciar una relación con Jorge.

El guión de la película pasó por la censura y se rodó de acuerdo con lo previsto, tras reunirse Buñuel con responsables de la Junta Censora. Tuvo pues un proceso largo como vemos a continuación.

En primer lugar, en el informe religioso moral del primer guión se señala que se trataba de un "guión cinematográfico, sin otra referencia alguna de autores, realizadores". Suponemos que para dejar claro que a Buñuel se le iba a tratar igual que al resto de directores españoles.

La censura prohibió este primer guión por varios motivos, pero sobre todo por el final que era muy explícito, ya que se detallaba cómo Viridiana, la joven religiosa protagonista, se entregaba a Jorge, el hijo bastardo de su tío. Un final del que luego Buñuel reconoció sentirse avergonzado por haberlo presentado de forma tan brusca.

La última escena, según la primera versión del guión que se conserva4, se desarrollaba así:

Int. Recámara de Don Jaime. Noche.

Close Up.

Jorge, que termina de lavarse las manos y los brazos, se los está secando con una toalla. Oye el golpear suave y breve de unos nudillos en la puerta y va a abrir. Frente a él está Viridiana. Su expresión es extraña, aparentemente de gran calma, pero dejando transparentar una gran agitación interior. Jorge ha quedado atónito al verla. Jorge: ¿Ocurre algo?

Ella no responde. Intenta mirarle a los ojos, pero vencida vuelve a bajarlos.

4 Expediente 53.167. Caja 71.847. Archivos del Ministerio de Cultura. 
Jorge: ¿Quería hablarme? ¿En qué puedo servirla?

Jorge intenta penetrar las intenciones de la muchacha. Es inútil. No comprende nada.

Viridiana entonces y por fin lo mira a los ojos suplicante, como pidiendo comprensión y perdón.

La concentrada expresión de Jorge se distiende. Hace tiempo que la quiere.

Se siente de pronto profundamente conmovido. Intuye el valor casi heroico de aquel carácter extraño. La sonríe con ternura y le pone sus manos en los hombros. La atrae dulcemente hacia sí y la hace pasar.

En la segunda versión el censor reconoce que en el final ${ }^{5}$ "se procede de modo más suave, teniéndose la conversación delante de Ramona, mientras juegan a las cartas creo... Por lo que se refiere a esto la adaptación es "potable" sic. Con lo que, realmente, lo que se planteaba era una relación de los tres, lo que se conoce como menage a trois.

Asimismo se insiste en las dos revisiones en el carácter autoritario con que se presenta a la superiora del convento donde está Viridiana.

El censor es explícito y rectifica el personaje: “la superiora es de un 'antipático subido', que no tiene justificación alguna en la trama: 'mandona': Te mando...te exijo...te dejo... Y cuando le pide perdón, Viridiana se marcha sin contestarle. También he tachado algunas de esas frases en los folios 57-58".

El censor insiste también en que Viridiana no debe aparecer en muchos planos como religiosa, tras haber abandonado el convento "es una piadosa extravagante. Ya está bien".

Insiste en que se ha de dejar claro que "D. Jaime no viola a Viridiana, y tener mucho cuidado con...los mendigos sublevados..., es de mal gusto, pero allá el Guionista con el valor artístico 'misterioso’ que envuelve esas escenas".

Finaliza el censor: "se señalan también algunas sugerencias...En general toda esa orgía habría de cuidarse para evitar posibles y ulteriores supresiones en la película ya realizada”.

Los informes de la censura se presentan entre el 15 de diciembre de 1959 y el 3 de enero de 1960.

El 20 de enero de 1961 se otorga el permiso para el rodaje desde la dirección general de cinematografía, insistiendo en que se han de cuidar las recomendaciones que se adjuntan en el informe del censor, así como que la versión válida es el segundo guión.

Expediente 53.167. Caja 71.847. Archivos del Ministerio de Cultura. 
El presupuesto de la película ascendió a 8,6 millones de pesetas (51.600 euros) de los que Buñuel percibió un millón de pesetas (6.000 euros) por su labor como director. Rabal cobró 600.000 pesetas (3.600 euros), Silvia Pinal 650.000 (3.900 euros) y Fernando Rey 300.000 pesetas (1.800 euros).

En el listado del equipo artístico hubo una variación ya que aparece María Luisa Ponte como la interprete de Ramona, papel que finalmente realizó Margarita Lozano.

El rodaje se inició el 16 de enero y se prolongó a lo largo de 65 días, de los que 27 fueron para rodajes en exteriores y 38 para interiores.

El permiso de rodaje lo solicitó Domingo González Lucas, en su calidad de director gerente de la productora Unión Industrial Cinematográfica, Uninci.

La película se presentó como una obra española, sin ningún tipo de ayuda extranjera.

\section{Premio de Cannes}

Mientras se ultima el rodaje se recibe la invitación para acudir al Festival de Cannes. España presenta No dispares contra mi (1960) y Viridiana. El 14 de marzo el vicepresidente de Uniespaña, Manuel Goyanes, solicita a las autoridades que se pida a la dirección del Festival una ampliación de 10 días para poder presentar ${ }^{6}{ }_{i}$ ridiana ya que dentro del mismo será posible efectuar un visionado de dimensión suficiente para emitir nuestro informe definitivo".

El 30 de marzo, el delegado general del Festival francés, Favre Le Bret, escribe una carta a Alatriste a la razón social de Uninci mostrándole su interés para que Buñuel participe con su nuevo trabajo en la edición de este año por lo que le pide la fecha en la que cree que el filme estará terminado.

Asimismo se cursa la invitación oficial al Estado español, la que responde el 14 de abril el director general de cinematografía José Muñoz Fontán donde se explica la decisión de presentar Viridiana al Festival.

El 25 de abril, Muñoz Fontán vuelve a escribir a Le Bret para comunicarle que tiene conocimiento de que están invitados oficialmente a Cannes con Viridiana y le comunica que dicha película ha quedado terminada a falta de sonorización que se piensa hacer en París.

Pese a la disposición de Fontán en España todavía no se había visionado la película y el 27 de abril el presidente de Uniespaña, Jorge Tusell, emite un escrito a la dirección general de cinematografía en la que se da

6 Expediente 53.167. Caja 71.847. Archivos del Ministerio de Cultura. 
cuenta de que el Consejo de Uniespaña acordó "lamentar el retraso con que ha tenido que ser visionada $V i$ ridiana y emitir un informe denegatorio sobre el envío de las películas No dispares contra mí y Viridiana”.

Esto inicia una serie de complicaciones, ya que la película llegó a Cannes, como representante de España, sin que las autoridades españolas tuvieran plena conciencia de lo que aquel filme representaba.

En Cannes, Viridiana recibe la mayor distinción, la Palma de Oro, ex-aequo, que recoge el propio Muñoz Fontán, pero poco después el Vaticano, a través de la publicación L'Osservatore Romano, la tachó de blasfema.

Esto provocó una situación extraña con respecto a la película, ya que perdió la nacionalidad española, (la recuperó en 1977), y contribuyó a que el Gobierno español fuera criticado desde los foros internacionales.

Tras ganar la Palma de Oro la película fue prohibida en España, y Gustavo Alatriste decide quedarse con los derechos de exhibición en el mundo, según los documentos, tras el pago de esa cesión?

Junto a ello Uninci, gestionada por miembros del PCE en la clandestinidad (Juan Antonio Bardem y Domingo González), perdió la titularidad para su exhibición internacional, de una película que se presentaba como una obra mejicana, pese a haber sido rodada en España y financiada con capital de nuestro país.

\section{Exhibición internacional}

A partir de una la copia que se llevó a París para el doblaje, se realizarán otras para su exhibición, labor que gestionará Alatriste, pese a que este no pagó sus derechos a Uninci.

Alatriste se puso en contacto, en agosto de 1961, con el embajador de España en Méjico, Joaquín Juste, para pedirle que intermediara para que el Gobierno español no pusiera trabas para la exhibición mundial, tal y como había acordado con Uninci. En el documento del embajador se indica que Alatriste le ha hecho una amenaza velada "de hacernos una campaña periodística en Paris Match, y en la prensa mejicana si España se obstina en poner obstáculos a la difusión de la película en el extranjero”.

Poco después se tiene conocimiento de que se ha publicado un anuncio en la revista francesa La cinematographie francaise donde se explica que Alatriste tiene los derechos para la exhibición mundial.

El Gobierno español comprende que la película se va a proyectar en todo el mundo. Por ello comienza a informarse de los medios que existen para prohibir su entrada en diversos países, como es el caso de Argentina, nación que apoyaba moral y económicamente al régimen franquista.

Expediente 53.167. Caja 71.847. Archivos del Ministerio de Cultura. 
Por otra parte se inician una serie de informes sobre Uninci ante la sospecha de que esta empresa, gestionada por miembros de PCE en la clandestinidad, pudiera estar haciendo un doble juego y facilitando copias del filme.

Esto provoca que desde Uninci se elabore un documento donde se detallan todos los pormenores del proceso. Incluso esta productora llegará pedir que se prohiba la proyección en Ginebra alegando su responsabilidad sobre la exhibición.

Desde la administración se realizan informes sobre las copias que circulan por Francia y Suiza y se elabora otro para el Ministro de Información y Turismo, donde se plantea la posibilidad de modificar la película en alguna parte y proyectarla de nuevo como trabajo español. Idea que no se realiza, por lo que el filme se presenta en Nueva York, Estocolmo y Londres. En Italia es secuestrada, lo que provocó una serie de manifestaciones en contra.

En 1968, el distribuidor Ismael Gonzále,s solicita permiso para la exhibición de la película mejicana Viridiana en los cines de Arte y Ensayo, permiso que es denegado. La película no será proyectada en España hasta 1977, año en que se le devuelve la nacionalidad.

\section{Influencias de Galdós}

El mundo de Viridiana es original de Buñuel y Alejandro, pero también es cierto que cuenta con muchos aspectos galdosianos como han puesto de manifiesto lo especialistas en Buñuel. Agustín Sánchez Vidal ${ }^{8}$, en su libro sobre la obra cinematográfica del realizador, asegura que Buñuel no es tan ajeno al mundo galdosiano como pudiera pensarse a primera vista. Es más, para Vidal, Viridiana podría considerarse como una réplica de Nazarín (Sánchez Vidal, 1984: 255).

En las enciclopedias e historias del cine, el planteamiento es similar a la hora de analizar la película, argumento análogo a Nazarín en clave femenina: "Muchos contactos con Nazarín" (Historia del Cine, 1986: 145). “Tema de Nazarín desarrollado con mayor profundidad y ferocidad” (Historia Universal del Cine, 1982: 54). "El guión original escrito por Alejandro y Buñuel, basándose en una historia original de ambos, mas cabe afirmar que se inspiraron en Galdós”(Historia del Cine, 1984: 345 ). Esas similitudes entre el mundo de Bu-

8 “Ciertos temas resuenan como armónicos en estos dos universos tan aparentemente alejados, y las relaciones más profundas, probablemente derivan de su común inserción en alguna variedad del krausismo. Eso es muy claro en la adaptación de Nazarín y hubiera salido reforzado de haberse rodado Ángel Guerra, proyecto que llegó a estar muy avanzado. Vuelve a quedar de relieve en Viridiana, la otra película rodada en España”. 
ñuel y Galdós, según los críticos, afloran en Viridiana, una película que el aragonés considera como la más personal (Aranda, 1975: 390) ${ }^{9}$.

Buñuel abunda en las vinculaciones con el novelista canario y reconoce que "es posible que la rebelión de los mendigos recuerde al final de Ángel Guerra” (Pérez Turrent; de la Colina, 1993: 133), cuestión que, para Sánchez Vidal, es elemental ya que en la película "se cuelan elementos de Ángel Guerra" (Sánchez Vidal, 1984: 221). La censura también lo consideró así, según detalla Arreita-Jauregui en su informe de Tristana.

El propio Julio Alejandro, guionista, no lo olvidemos, de Nazarín, Tristana y Viridiana, reconoce ver detrás de la película el espíritu de Galdós, de las mujeres galdosianas (Aub, 1985: 392).

Lo cierto es que Buñuel mostró siempre un interés por la novela galdosiana Ángel Guerra. Así se lo confesó a Vidal, para quien esta predilección por esta novela obedece "a que en Ángel Guerra conviven espiritualismo y positivismo” (Sánchez Vidal, 1984:227), batalla permanente a lo largo de toda Viridiana, dado los intereses de esta mujer, que ha de enfrentarse a diario con la fría y descarnada realidad que le circunda.

La película plantea muchos aspectos del mundo galdosiano que Buñuel compartía: los mendigos, el viejo caballero, los místicos de lucha diaria, las relaciones adúlteras o la insolidaridad humana. Todos estos puntos es posible que se encuentren en otras películas del aragonés, pero lo que es propio y particular en este caso es el personaje principal, Viridiana, que es un trasunto de Leré, la coprotagonista de Ángel Guerra.

\section{Viridiana: espejo del mundo buñuelesco}

La idea original de la película, según declaraciones de Buñuel, el embrión inicial era una fantasía erótica que él tenía en la que suministraba un narcótico a la Reina Victoria Eugenia para abusar de ella, a la que unía la historia de una santa llamada Viridiana (Buñuel, 1982: 227). A partir de esto, desarrolló toda una historia, pero sin un guión cerrado, por lo que es lógico que se introdujeran elementos de su ideario personal. Julio Alejandro afirma que esta película "se hace paulatinamente y desarrollando poco a poco el argumento" (Aub, 1985: 223).

De la plasmación de esas ideas dará cuenta el mismo Buñuel, (Aranda, 1975: 398) ${ }^{10}$. Julio Alejandro con-

\footnotetext{
9 “Viridiana es el film que está más cerca de mis tradiciones personales de realización de cine desde $L^{\prime}$ âge d’or. Son las dos obras que dirigí con mayor sensación de libertad. Volví de México a España porque podía trabajar allí con libertad. Hice Viridiana con esa libertad... La educación religiosa y el surrealismo han dejado marcas indelebles en mi vida. Viridiana tiene la mayor parte de los temas que me son más cercanos y que más me interesan”.

10 "Soy un hombre que a veces pienso y tengo ideas. Y las puse en Viridiana. No quiero decirles cuáles son. Quiero que el público decida.
} 
firma la declaración de Buñuel en su larga entrevista con Aub y concreta el interés del realizador por la religión (Aub, 1985: 46) ${ }^{11}$.

Unos elementos buñuelescos que en un primer momento no fueron captados por la censura española, pero que la Iglesia Oficial y Vaticana rechazó. La intención del realizador es conmover, alertar a la sociedad y mostrarle lo descarnado de algunas situaciones, llegando incluso al escándalo y la blasfemia.

Esto último en ocasiones no buscado de forma directa, sino que a través de juegos del subsconciente, asociaciones mentales, de nuevo el surrealismo, afloraban cuestiones como la del crucifijo-navaja. Buñuel le explicó a Buache la cuestión (Buache, 1976:56) ${ }^{12}$, asegurándole que su hermana, que era muy religiosa, había visto en una ocasión a una monja pelar una manzana con un cristo-navaja. Buñuel ha mantenido siempre la misma postura sobre las opiniones que desata el crucifijo-navaja, así en el prólogo a una de las publicaciones del guión de la película asegura que "la fotogenia ha transformado su significado. Una vez proyectada sobre la pantalla, una navaja, utilizada por doquier en España,... se ha convertido en blasfema y sacrílega”.

Otro elemento que aparece en varias ocasiones es la comba, con que se inicia la película, con la que se ahorcará D. Jaime y que servirá a uno de los mendigos como cinturón, en el momento que trata de forzar a Viridiana. La presencia de cuerdas, de sogas es algo habitual en su filmografía desde Un perro andaluz. Aparecerán en filmes como Abismos de pasión (1954), o Nazarín (1958), y también en Viridiana donde se convierten "en una visualización del vínculo carnal entre los distintos personajes" (Martínez Herranz, 2009: 107).

Donde sí que buscó Buñuel impactar al espectador fue en aspectos como la compra infructuosa del perro, que no evita que haya crueldad similar con otros. Esto ha sido reconocido por el propio director quien afirma que "esta pequeña parábola es casi una crítica marxista de la parábola del Buen Samaritano" (Durgnat, 1973: 132).

Además Buñuel incorporará sus símbolos más peculiares, como son las piernas y el pie, la adoración por este miembro del cuerpo de una mujer, como vemos cuando Viridiana se quita las medias, pero también desde el inicio del filme, ya que el primer enfoque deViridiana es un plano inclinado a lo largo de la comba de una

Viridiana es yo. Es un recuerdo de cosas pasadas, cosas de cuando era niño, que recuerdo bien. Deseo que el público se asocie con mis experiencias".

11 "La cuestión religiosa, obsesión más bien, nace en su infancia. Todo eso le atrae de una manera muy fuerte y lo ha estudiado enormemente... Un ejemplo clásico: El milagro de Calanda".

12 "Está claro que yo no he inventado el cristo-navaja-automática. Únicamente la fotografía es capaz de significar la malicia y el carácter surrealista de un objeto como este, que se fabrica en serie". 
niña, empezando desde su pie y enfatizando el fetiche del hombre que la espía. Durante la película Buñuel llegó a rodar 70 planos de pies, unos los mantuvo y otros los eliminó en el montaje final (Sánchez Vidal, 1984: 257). Esa necesidad de convertir la obra fílmica en un revulsivo, en un manifiesto subversivo arranca, ya desde sus primeras producciones surrealistas, que se englobaron en un movimiento "ansioso de adquirir una instrumentalidad político-cultural” (Gubern; Hammond, 2009: 14), afín a los sectores comunistas de la URSS de aquel entonces. Es decir, vinculándose con la izquierda más reaccionaria, del momento.

Tampoco podemos dejar pasar las influencias de Salvado Dalí y Federico García Lorca en la obra de Buñuel, que también aparecen reflejadas en Viridiana. En la película la protagonista arrojará al fuego las agujas y lanas como preludio de su abandono del convento. Se asocia así la traición, el abandono amoroso, con la figura de una mujer que cose o teje. En Tristana, cuando D. Lope recela que esta le engaña, se ve a la protagonista tejiendo. Sánchez Vidal nos recuerda la fascinación que Dalí sintió durante toda su carrera por el cuadro La Encajera de Vermeer, que incluso llegó a recrear.

Las similitudes con Lorca también se dan, como es el caso de cuando la niña, la hija de la criada, dice que "ha venido un toro negro", figura lorquiana por excelencia. Sánchez Vidal profundiza más y explica cómo la secuencia en que se duerme a Viridiana parece sacada de una estrofa de la Oda al Santísimo Sacramento de Lorca, que dice (García Lorca, 1983: 25) "que al balido reciente y la flor desnortada y a los senos sin huellas de la monja dormida responda negro toro de límites maduros con la flor de un momento sin pudor ni mañana".

Lo cierto es que el conjunto de la película logró conmover, provocó reacciones entre los espectadores, lo que le hizo convertirse, por su prohibición tras su estreno en 1961, y por la quema de sus copias, en una de las películas de culto de este país. La llegada de la democracia permitió su visión completa y sin trabas en España, a partir de 1977 tras obtener de nuevo la nacionalidad española, que había perdido. Por ello hubo eclosión de proyecciones de Viridiana en salas privadas, los cine-clubs y hasta los institutos de bachillerato ${ }^{13}$.

\section{Surrealismo para conmover}

El impacto de la película obedece sobre todo a sus pilares surrealistas, algo que le servía al realizador para mostrar su ideario. Él mismo reconoce (Pérez Turrent; de la Colina 1993: 124) que la obra no es surrealista por contar con una trama argumental lógica, "tiene un argumento lógico, una consecuencia en los hechos, una verosimilitud...Pero sí hay un espíritu surrealista en el significado de la película y también en su humor".

13 El autor de este trabajo visionó la película por vez primera en el centro donde estudiaba BUP. 
Los investigadores de Buñuel han entendido que la actitud surrealista de la película es la que ataca a la sociedad y a los valores religiosos: "el incendio surrealista que provoca con su Viridiana ilumina a los hombres y carboniza los valores de una sociedad solapadamente opresiva” (Buache, 1976: 87).

Esta moralidad le viene imbuida a Buñuel por el propio surrealismo. El realizador reconoce que de sus años de militancia en el movimiento artístico “conservo, más allá de todo descubrimiento artístico....una exigencia moral clara e irreductible a la que he tratado de mantenerme fiel contra viento y marea" (Buñuel, 1982: 121).

La ideología marxista de Buñuel y el misticismo español más puro, alejado de la iglesia oficial, esos santos de acción, tal vez pueden lograr, como la parábola marxista del Buen Samaritano, ayudar a la sociedad de forma más directa. Curiosamente Cernuda ya destacó esta premonición en Galdós (Cernuda, 1994: 519) ${ }^{14}$.

Esta revolución se puede dar por el personaje protagonista, Viridiana, y por su trasunto, quien al igual que $\mathrm{Na}$ zarín (Correa, 1979: 158) lleva el germen de la revolución social. Y en esta revolución social volvemos a toparnos con el surrealismo, que según Buñuel (Buñuel, 1982: 121) "fue un llamamiento que sonaba por primera vez con tal fuerza, con tal vigor, en medio de una singular insolencia... contra todo lo que nos parecía nefasto”.

Ideas que él mantuvo hasta el final y que plasmó en cada uno de los planos de las andanzas de Viridiana, sombra y reflejo de otro ente ficticio, Leré. Sin embargo, pese a ser creadas por la mente del novelista y el director, ambas son muestra del prototipo de mujer española, inmersas en la tradición hispánica, que tan bien captaron nuestros dos genios.

Viridiana, treinta años después de las primeras proyecciones surrealistas en París, mantenía muchos de los aspectos convulsivos y subversivos del surrealismo, por ello la convirtieron en un icono, en un símbolo del ideario revolucionario, lo que la ha llevado a superar con creces el paso del tiempo y convertirse en una de las obras más valiosas del realizador aragonés y referente de una corriente creativa que enriqueció el lenguaje cinematográfico y que todavía aflora entre determinado grupo de cineastas independientes.

\section{Conclusión}

Buñuel fue un exponente continuo del surrealismo, ya que potenció todos sus componentes, los desarrolló e hizo que evolucionaran a la par de su trayectoria, logrando incluso que el ideario vanguardista se

14 "Advierte que acaso las creencias religiosas, tal como las concibió el pueblo español, a través de los siglos, puestas de nuevo en contacto con el mundo contemporáneo, con las ideas del socialismo naciente, modernizadas, diríamos, resultaran de momento más útiles". 
entremezclara en su mundo particular, y a la inversa, con lo que otorgó un sello peculiar a su trabajo. El universo fílmico de Buñuel parte de lo real, de lo concreto del mundo establecido, para llegar en ocasiones a situaciones irreales, ilógicas y hasta oníricas, facilitadas al espectador a través de elementos surrealistas. Buñuel continuó introduciendo, captando elementos surrealistas dentro de su filmografía. El surrealismo dejó su señal a lo largo de toda su obra en los filmes realizados por Buñuel con posterioridad a La Edad de Oro. En algunas ocasiones la situación o el argumento podría ser considerado "surrealista" como El discreto encanto de la burguesía (1972) o La Vía Láctea (1969), pero habrá otras como Tristana (1970) o Viridiana, cuyo libreto es realista, y el planteamiento de la película resulta de lo más estricto y hasta documental, en las que el surrealismo aflora en determinadas escenas, situaciones, diálogos u objetos, que impactan en el receptor.

El ideario surrealista, las imágenes o las situaciones surrealistas podrán aparecer, por ejemplo, en secuencias oníricas, o por la disposición o el ensamblaje de ciertos elementos icónicos en el interior de determinados planos. En un mundo donde se violan las leyes del orden natural y social. Hay por tanto una intencionalidad surrealista en sus películas, como forma de provocar emociones, sensaciones en quien recibe el discurso fílmico, como podemos comprobar con la pervivencia de los valores de Viridiana. Esos valores llegan al espectador a través de los impactos, las descargas surrealistas que Buñuel, bien conocedor del movimiento, lanza fogonazos con los que deslumbrar y dar en la retina y el corazón. Hay una intencionalidad a la hora de realizar sus películas, los tintes surrealistas no afloran porque sí, sino que es una labor de trabajo previa. Buñuel demuestra que la experiencia surrealista ha tenido su sentido, que ha valido para aportar nuevos elementos al arte mundial, sobre todo si tenemos en cuenta que el cine es una de las manifestaciones artísticas más populares. En Viridiana, Buñuel se sirve de esos elementos surrealistas para subrayar la denuncia que plantea el argumento narrativo, para enfatizar en la acusación y crítica a determinados estamentos y valores que desarrolla en el guión original. Las imágenes y situaciones surrealistas servirán para incidir mucho más en el valor subversivo que el realizador aragonés plantea en argumentos como el de este filme, que todavía, medio siglo después de su estreno, no ha perdido un ápice de ese carácter transgresor.

\section{Referencias bibliográficas}

Aranda, Francisco (1975): Biografía Crítica, Barcelona: Lumen.

Aub, Max (1985): Conversaciones con Buñuel, Madrid: Aguilar.

Buache, Fredy (1976): Luis Buñuel, Madrid: Labor. 
Buñuel, Luis (1982): Mi último suspiro, Barcelona: Plaza y Janés.

Cernuda, Luis (1994): Obra Completa. Prosa. I Galdós (1954), Madrid: Siruela.

Correa, Gustavo (1979): “Tradición. Mística y Cervantismo en las novelas de Galdós. 1890-97”, en Rogers, Douglas: Benito Pérez Galdós. El escritor y la crítica. Madrid: Taurus.

Durgnat, Raymond (1973): Luis Buñuel, Madrid: Fundamentos.

García Lorca, Federico (1983): Obras Completas. II, Madrid: Alianza Editorial.

Goytisolo, Juan (2007): Contra las sagradas formas, Barcelona: Círculo de Lectores. Galaxia Gutemberg.

Gubern, Román; Hammond Paul (2009): Los años rojos de Luis Buñuel, Madrid: Cátedra.

Martínez Herranz, Amparo (2009): “Del decoupage a la mariposa; construyendo métodos y temas”, en AA.VV.: Un perro andaluz, ochenta años después. Madrid: La Fábrica Editorial.

Muñoz Molina, Antonio (2008): “Oro y bisuterías de Dalî”, Babelia, El País, 12-07-08.

Pérez Turrent, Tomás y. De la Colina, José (1993): Buñuel por Buñuel, Madrid: Ediciones Plot.

Salvador, Alicia (2006): De Bienvenido Mr. Marshall a Viridiana, Madrid: EGEDA.

Sánchez Vidal, Agustín (1984): Luis Buñuel. Obra Cinematográfica, Madrid: Ediciones J.C.

\section{MANUALES}

Historia Universal del Cine.Vol. XI. Madrid: Planeta. 1982.

Historia del Cine. Vol. IV. Madrid: Sarpe. 1984.

Historia del Cine. Vol. I. Madrid: Diario 16. Información y Prensa. 1986.

REVISTAS

Boletín de la Academia de las Artes y Ciencias Cinematográficas 